\title{
O RESIDENTE IDEAL EM RADIOLOGIA E DIAGNÓSTICO POR IMAGEM*
}

\author{
Evandro Guimarães de Sousa ${ }^{1}$, Hilton Augusto Koch ${ }^{2}$
}

Resumo A Comissão Nacional de Residência Médica, em 2003, estabeleceu novos critérios para o credenciamento de programas de Residência Médica em Radiologia e Diagnóstico por Imagem. Apesar dessas normas representarem um avanço no treinamento do residente, outras competências e habilidades específicas deverão ser desenvolvidas no sentido de acompanhar o rápido desenvolvimento técnico e científico, e para atender as novas exigências do mercado de trabalho. Os autores apresentam as principais competências e habilidades que complementam a formação do radiologista, sugerindo modificação nos atuais programas para que os residentes possam adquiri-las.

Unitermos: Residência médica; Radiologia; Diagnóstico por imagem; Residente; Educação.

Abstract The ideal medical resident for radiology and imaging diagnosis.

In 2003, the National Committee of Medical Residency established new criteria for the accreditation of Radiology and Imaging Diagnosis Residency programs. Although these rules represent an advance to the resident's training, other specific abilities and skills should be developed in order to keep up with the technical and scientific advances and with the new requirements of the career. The authors' present the must important competencies and skills that complement the radiologist's education and suggest a change in current programs so that the resident can acquire these competencies and skills.

Key words: Medical residency; Radiology; Image diagnostic; Resident; Education.

A Comissão Nacional de Residência Médica (CNRM) determinou, em 2003, os critérios mínimos para o credenciamento de programas de Residência Médica em Radiologia e Diagnóstico por Imagem.

De acordo com esses critérios, durante o período de três anos, o residente deve adquirir competências em radiologia geral e contrastada, ultra-sonografia, mamografia, tomografia computadorizada, densitometria óssea, ressonância magnética, radiologia intervencionista, técnicas de exames, urgências e emergências, desenvolvidas em um programa de treinamento que deve corresponder a, no mínimo, $80 \%$ do planejado a cada ano, complementado pelas atividades teórico-complementares, cuja carga horária pode oscilar entre 288 a 576 horas anuais.

* Trabalho realizado no Departamento de Radiologia da Faculdade de Medicina da Universidade Federal do Rio de Janeiro (UFRJ), Rio de Janeiro, RJ.

1. Doutor em Radiologia pela Faculdade de Medicina da UFRJ, Professor do Curso de Especialização em Fisioterapia do Centro Universitário do Triângulo, Uberlândia, MG.

2. Professor Titular do Departamento de Radiologia da Faculdade de Medicina da UFRJ.

Endereço para correspondência: Dr. Evandro Guimarães de Sousa. Rua Coelho Neto, 520. Uberlândia, MG, 38400-286. E-mail: evansousa@hotmail.com

Recebido para publicação em 22/8/2003. Aceito, após revisão, em 12/11/2003.
Essas atividades teóricas devem prever sessões anátomo-clínicas, discussão de artigos científicos, sessões clínico-radiológicas, cursos, palestras e seminários, além das discussões sobre temas de Bioética, Ética Médica, Metodologia científica, Epidemiologia e Bioestatística ${ }^{(\mathbf{1})}$.

Alguns programas dessa especialidade podem ainda oferecer, em um quarto ano opcional, treinamento nas áreas de atuação em angiorradiologia e cirurgia endovascular, ecografia vascular com Doppler, neurorradiologia, radiologia intervencionista e angiorradiologia $^{(2)}$.

Diante dos constantes avanços científicos e tecnológicos e das atuais exigências do mundo do trabalho, é necessário, para assegurar o sucesso do futuro especialista em radiologia e diagnóstico por imagem, além do que lhes é oferecido tradicionalmente em programas de Residência Médica, a aquisição de novas competências e habilidades específicas que compõem o perfil do residente ideal, cujas principais características são as seguintes ${ }^{(\mathbf{3})}$ :

- Depois de cumprir a jornada de treinamento de 60 horas semanais, estipulada na legislação em vigor, o residente estará disponível para permanecer mais tempo no serviço enquanto puder desenvolver ativi- dades interessantes para complementar a sua formação.

- Deve possuir um conhecimento diferenciado em relação aos demais, o que é caracterizado pela habilidade de selecionar o mais importante do seu saber e aplicá-lo na situação específica, demonstrando perfeito preparo para tal.

- Deve possuir habilidades técnicas superiores aos seus colegas, que lhe permitem desenvolver com propriedade tarefas tais como manipulação de um transdutor do ultra-som, obtenção de acesso vascular, realização de biópsias com visualização de imagem, além do competente uso de novas tecnologias, como sistema de informação e de comunicação em radiologia, arquivo de imagens e na otimização de imagens no computador. Deve apresentar um bom desempenho na obtenção de consentimento informado pelos clientes na interconsulta com médicos que solicitaram exames e no relacionamento com pacientes e seus familiares.

- É muito importante possuir espírito inquiridor, estudando assuntos relacionados ao seu treinamento, aprofundando seu conhecimento através de leitura e na busca de orientações a outros médicos, no sentido de aprender mais. Trabalhar com esse 
residente constitui uma gratificante experiência para o preceptor. Mesmo o mais experiente radiologista sente-se estimulado a continuar aprendendo e crescendo profissionalmente.

- Deve fazer dos erros cometidos parte do processo natural da aprendizagem e entender que uma postura de reconhecêlos e tentar aprender com eles o distinguirá de outros que, por constrangimento, os acobertam, prejudicando o paciente.

- Deve estar atento às expectativas do preceptor, professor ou outro membro do "staff", executando suas tarefas com disposição e presteza, ao mesmo tempo em que busca assegurar a qualidade no cumprimento dessas tarefas e adquire experiência profissional, através de estratégias que garantam o desenvolvimento de uma rotina mais tranqüila no serviço.

- Espera-se dos melhores residentes, daqueles destinados a exercer a liderança na profissão, a disposição para ajudar outros colegas, considerando-os muito menos como competidores e mais como auxiliares e a quem dão exemplo no cumprimento do horário estipulado e na permanência em serviço até o término de suas obrigações, as quais cumpre com rigor e competência.

- Além da expectativa de um brilhante nível técnico, algumas qualidades éticas e humanas devem fazer parte do caráter do residente ideal, como a honestidade, a capacidade de manter o sigilo das informações confidenciais declaradas pelos pacientes, generosidade no trato com seus pares, buscando estar sempre acessível para interação com outros profissionais da área da saúde e o público em geral $^{(\mathbf{3 , 4})}$.

- Deve aproveitar todas as oportunidades que lhe são oferecidas para pesquisar, participar de encontros que lhe permitam apresentar trabalhos, ministrar aulas, pro- ferir palestras como voluntário e quaisquer outros procedimentos que ampliem seu aprendizado $^{(\mathbf{5 , 6})}$.

- Deve reconhecer que a principal missão do seu treinamento é oferecer um atendimento com qualidade para o paciente. Deve, também, estar ciente de que a atenção para a saúde requer a realização dos serviços dentro dos padrões estabelecidos de qualidade, respeitando os preceitos da Bioética e da Ética Médica, e tendo em conta que a responsabilidade dessa atenção não se encerra com o ato técnico, mas sim, com a resolução do problema detectado ${ }^{(6,7)}$.

- Deve possuir competência para desenvolver a comunicação verbal e a não verbal, domínio da escrita e interpretação da leitura $^{(6,8)}$.

- Deve possuir a competência para gerenciar e administrar tanto a força de trabalho quanto os recursos físicos, materiais e de informação, devendo, portanto, exercer suas futuras atividades com espírito empreendedor e como gestor capaz de assumir a liderança de equipe de saúde ${ }^{(\mathbf{5 , 9})}$.

Para assegurar ao residente constante atualização em sua formação e possibilitar sua participação efetiva na prestação de serviços em saúde, é necessário que a Educação em Radiologia e Diagnóstico por Imagem seja revista periodicamente. Além das competências e habilidades relacionadas, outras deverão ser acrescentadas, como a capacidade de adaptar-se à evolução da especialidade, de lidar com problemas e tomar decisões em situações não familiares, de ser criativo e desenvolver espírito crítico, de estar apto para utilizar a medicina baseada em evidências científicas, de proceder à avaliação crítica de artigos científicos, de utilizar as várias formas de informação para a sua educação continuada, dentre outras ${ }^{(\mathbf{9 , 1 0})}$.
Os residentes em radiologia e diagnóstico por imagem devem ser encorajados a refletir sobre o propósito de seu treinamento, o que realmente desejam alcançar e como consegui-lo. Por outro lado, os preceptores devem rever os objetivos propostos para o programa, buscando incluir competências que complementem a formação dos residentes, além de auxiliá-los a encontrar mecanismos para adquiri-las.

\section{REFERÊNCIAS}

1. Brasil. Ministério da Educação. Secretaria de Educação Superior. Comissão Nacional de Residência Médica. Resolução no 4 de 2003. Dispõe sobre os requisitos mínimos para credenciamento de programas de Residência Médica e dá outras providências. Disponível em: <http://www.mec.gov.br/sesu/ pdf/cnrm_042003.pdf>. Acessado em 1/10/2003.

2. Brasil. Conselho Federal de Medicina. Resolução no 1.666 de 2003. Dispõe sobre o convênio de reconhecimento de especialidades médicas firmado entre o Conselho Federal de Medicina, a Associação Médica Brasileira e a Comissão Nacional de Residência Médica. Disponível em: <http://www. cfm.org.br>. Acessado em 1/10/2003.

3. Gunderman RB, Jackson VP. What makes a great radiology resident? Acad Radiol 2003;10:554-8.

4. Gunderman RB. A vital skill for radiology education. Acad Radiol 2001;8:651-5.

5. Harolds JA. Residents: be aggressive in your own education! Acad Radiol 1998;5:655-7.

6. Brasil. Ministério da Educação. Conselho Nacional de Saúde. Resolução CNE no 4 de 7 de novembro de 2001. Institui Diretrizes Nacionais Curriculares do Curso de Graduação em Medicina. Disponível em: <http://www.mec.gov.br〉. Acessado em 26/6/2003.

7. Collins J. Curriculum in radiology for residents: what, why, how, when and where. Acad Radiol 2000;7:108-13.

8. McLoud TC. Education in radiology: challenges for the new millennium. AJR 2000;174:3-8.

9. Collins J, de Christenson MR, Gray L, et al. General competencies in radiology residency training: definitions, skills, education and assessment. Acad Radiol 2002;9:721-6.

10. Sluming V. Commentary: the changing world of radiography education. Br J Radiol 1996;69:489-90. 